\title{
ADEQUABILIDADE, EFICÁCIA, SUBPRODUTOS E (NÃO) PRESCRIÇÃO DA PUNIÇÃO EM B. F. SKINNER (1930-1990)
}

\author{
ADEQUABILITY, EFFECTIVENESS, BY-PRODUCTS AND (NON) PRESCRIPTION OF PUNISHMENT \\ IN B. F. SKINNER \\ BRUNA COLOMBO dOS SANTOS \\ Pontifícia Universidade Católica de São Paulo/Universidade Estadual de FeIRA de Santana, Brasil
}

\author{
MaRcus Bentes de Carvalho Neto \\ UNIVERSIDADE FEDERAL DO PARÁ, BRASIL
}

\begin{abstract}
RESUMO
Skinner tem sido identificado na literatura analítico comportamental como um autor contrário a utilização da punição ou do controle aversivo em geral. Alguns estudos analisaram algumas obras do autor e identificaram que Skinner ressalta mais pontos negativos do que positivos com relação ao uso do controle aversivo. O objetivo desse estudo foi estender as análises realizadas nos trabalhos anteriores utilizando documentos (artigos, capítulos, livros completos, entrevistas e autobiografias) publicados por Skinner entre 1930 e 1990, com relação à adequabilidade, eficácia, subprodutos e prescrição ou não prescrição da punição. Os resultados indicaram que Skinner apresentou mais descrições classificadas como negativas com relação à adequabilidade, eficácia e subprodutos da punição. Os subprodutos foram classificados em genéricos e específicos. Por fim, os dados foram discutidos em relação a um cenário mais amplo com relação à pesquisa e representação da Análise do Comportamento.

Palavras-chave: Skinner, punição, Análise do Comportamento, pesquisa histórico-conceitual.
\end{abstract}

\begin{abstract}
Skinner has been identified in behavior analytic literature as an author contrary to the use of punishment or aversive control in general. Some studies analyzed some works of the author and identified that Skinner highlights more negative than positive points regarding to the use of aversive control. The aim of this study was to extend the analysis made in the previous studies using documents (articles, chapters, books and autobiographies) published by Skinner between 1930 and 1990, regarding to adequacy, effectiveness, by-products and prescription or non-prescription of punishment. The results indicated that Skinner presented more descriptions classified as negative regarding to adequacy, effectiveness, and by-products of punishment. By-products were classified as generic or specific. By the end, the data were discussed in relation to a broader scenario of research and representation of Behavior Analysis.
\end{abstract}

Key words: Skinner, punishment, Behavior Analysis; historical-conceptual research.

DOI. 10.18542/rebac.v14i2.7534 
$\mathrm{Na}$ literatura analítico-comportamental, Skinner é frequentemente identificado como um autor contrário ao uso da punição ou de controle aversivo em geral (Balsam \& Bondy, 1983; Crosbie, 1998; Hineline 1984; Skiba \& Deno, 1991; Todorov, 2001; Critchfield, 2014). Um dos motivos pelos quais o autor é identificado como contrário ao uso da punição refere-se aos seus subprodutos ou efeitos colaterais (Balsam \& Bondy, 1983; Crosbie, 1998; Hineline, 1984).

Alguns estudos têm se dedicado a identificar momentos em que Skinner prescreve ou adverte sobre o uso de controle aversivo em geral, em textos específicos (Martins, Carvalho Neto, \& Mayer, 2013; Martins, Carvalho Neto, \& Mayer, 2017). Martins, Carvalho Neto e Mayer (2013) analisaram oito obras ${ }^{1}$ de Skinner buscando identificar aspectos negativos e restrições quanto ao uso do controle aversivo apresentadas pelo autor, bem como aspectos positivos e prescrições. De maneira geral, os dados mostraram que em alguns momentos Skinner parece justificar o uso do controle aversivo, embora não o prescreva genericamente.

Martins, Carvalho Neto e Mayer (2017) investigaram a utilização ou não de controle aversivo na sociedade utópica delineada por Skinner, "Walden II". Os autores identificaram três momentos em que controle aversivo foi prescrito: (1) controle aversivo do rebanho através da cerca elétrica; (2) ensino de autocontrole; e (3) expansão territorial.

Este trabalho vai na direção dos trabalhos supracitados (Martins, Carvalho Neto, \& Mayer, 2013; Martins, Carvalho Neto, \& Mayer, 2017). Todavia, por uma perspectiva, ele restringe as análises ao conceito de punição, e não "controle aversivo" em geral. De outra perspectiva, ele expande as análises ao incluir textos (artigos, livros, capítulos de livro, entrevistas e autobiografias) de Skinner entre 1930 e 1990.

Sendo assim, este texto é fruto de trechos encontrados durante a análise dos documentos publicados por Skinner, entre 1930 e 1990, onde ele utilizou o conceito de punição para descrever ou explicar fenômenos humanos individuais ou culturais. Buscou-se analisar tais trechos considerando se o autor analisava ou não a adequabilidade, eficácia e subprodutos da punição, e se havia argumentações sobre se a punição deveria ou não deveria ser utilizada.

Dittrich e Abib (2004) afirmam que, do ponto de vista moral, há uma tensão constante na obra de Skinner entre descrição e prescrição. Essa tensão pode ser compreendida dentro da análise do comportamento verbal como uma tensão entre tatos e mandos. Descrever é tatear uma situação, comportamento ou evento, no sentido de que o comportamento verbal do cientista é controlado, em grande parte, pela situação, comportamento ou evento, e produz reforçadores generalizados. Prescrever é um mando,

\footnotetext{
${ }^{1}$ The Behavior of Organisms: an experimental analysis (1938); Walden II (1948); Science and Human Behavior (1953/2005); The Technology of teaching (1968); Beyond and Freedom and Dignity (1971/2002); About Behaviorism (1974/1976); Contingencies of Reinforcement: a theoretical analysis (1969/1980); Recent Issues in the Analysis of Behavior (1989)
}

pois a resposta especifica um determinado reforçador a ser fornecido pelo ouvinte. Nas palavras de Dittrich e Abib (2004): “... um discurso descritivo é aquele que diz 'X é assim"; um discurso prescritivo, por outro lado, é aquele que diz: 'X deveria ser assim'”' (p. 428).

Essa tensão também parece estar presente no campo da punição. $\mathrm{O}$ conceito de punição foi utilizado por Skinner para descrever ou explicar determinados processos comportamentais e fenômenos humanos individuais ou culturais. Nesse aspecto, Skinner tomou a punição como uma variável importante que entra na descrição e explicação desses fenômenos (e.g., sentenças do tipo "a punição é utilizada no treino ético" ou "a punição é usada como técnica de autocontrole"). Em análise da obra do autor, Santos (2017) identificou inúmeros tópicos sobre os quais Skinner recorre à punição em sua análise (e.g., punição em Walden II; autocontrole, tomada de decisão, resolução de problemas e autoconhecimento; dinamismos Freudianos e "traços" de personalidade; controle pessoal e controle pelo grupo (agências); treinamento ético, cultura e planejamento cultural; problema do controle e contra controle; liberdade, dignidade e responsabilidade; punição no comportamento verbal; punição e educação).

Entretanto, Skinner foi além disso, ele também descreveu a punição em termos de sua adequabilidade, eficácia e subprodutos (e.g., sentenças do tipo "a punição não funciona em longo prazo" ou "a punição produz emoções desagradáveis"). Nessas descrições, nota-se a presença de autoclíticos qualificadores (e.g., indesejável, desvantajoso, prejudicial). Nesses casos, a distinção entre descrição e prescrição fica mais tênue, pois a função desses dois tipos de sentença pode ser a mesma (mando). Por exemplo, a sentença "a punição não deve ser utilizada" e a sentença "a punição produz infelicidade", formalmente, poderiam ser classificadas como prescritiva e descritiva, respectivamente. Mas se o efeito sobre o comportamento do ouvinte for o mesmo, perde-se a base funcional da distinção (Dittrich, 2004).

Reconhecida essa possibilidade, parte-se para análise das sentenças formalmente prescritivas, aquelas nas quais Skinner foi explícito no uso do termo "deve", ou mais especificamente, no caso da punição, do termo "não deve". Notou-se, portanto, uma "não" prescrição da punição em alguns momentos da obra Skinneriana (e.g., sentenças do tipo "a punição não deve ser utilizada no planejamento cultural").

Nosso objetivo foi identificar em que momentos Skinner apresenta descrições sobre adequabilidade, eficácia e subprodutos da punição, e apresenta prescrições ou não prescrições da punição para o controle do comportamento humano. Não foi nosso objetivo exaurir as discussões sobre cada tópico, nem tampouco examinar as afirmações de Skinner minuciosamente, contrastando-as com dados de pesquisa, como por exemplo, faz Critchfield (2014) ao demonstrar dados que sugerem importância da punição na manutenção do comportamento de cooperar. A ideia desse texto é que ele seja um levantamento das prescrições ou não prescrições de Skinner sobre punição ao longo de sua obra, de forma que o leitor possa ter um material completo para consulta sobre esse tema. 


\section{MÉTODO}

Critérios de seleção inicial - artigos, livros completos, capítulos, entrevistas e autobiografias

Foram utilizadas obras completas, artigos, capítulos e entrevistas publicados por B. F. Skinner ao longo dos 60 anos de sua produção. Estes documentos foram levantados com base na lista produzida por Andery, Micheletto e Sério (2004), pois é a mais recente e compila todas as produções do autor entre 1930 e 2004 (publicações póstumas). Os documentos publicados por Skinner apresentam, por vezes, reedições e republicações, trabalhou-se preferencialmente com os documentos originais (primeira edição e primeira publicação). Quando os originais não foram encontrados, foram selecionadas reedições ou republicações.

Foram selecionados inicialmente para análise os seguintes documentos entre 1930 e 1990: (1) Artigos em periódicos e/ou revistas - foram selecionados artigos sobre (a) punição ou controle aversivo (experimentais, teóricos ou técnicos); (b) análises sociais/éticas e/ou controle do comportamento do humano; (c) revisita a obras publicadas - artigos em que Skinner comenta sobre publicações anteriores; (d) Conhecimento pessoal do autor - artigos que o autor deste trabalho já tinha lido previamente e que foram considerados relevantes para a pesquisa, porém não se encaixaram em nenhum dos critérios anteriores; (2) Livros completos e/ou capítulos - foram selecionados todos os livros publicados por Skinner entre 1930 e 1990, exceto "Enjoy the Old Age: A program of self management" (Skinner \& Vaughan, 1983); (3) Entrevistas - foram selecionadas todas as entrevistas concedidas por B. F. Skinner; (4) Autobiografias Particulars of my life: Part one of an autobiography (Skinner, 1976b); The shaping of a behaviorist: Part two of an autobiography (Skinner, 1979a); e A matter of consequences: Part three of an autobiography (Skinner, 1983).

\section{Critérios para inclusão e exclusão dos documentos selecionados de acordo com o critério inicial}

Depois da seleção inicial, identificou-se se os documentos continham as seguintes categorias de registro: punish* (punishment, punished, punisher, punishg); punitive; negative conditioning; negative reinforcement; avers* (aversive; aversion; aversivily) side effects; by-products; emotional; reserve; avoid* (avoid, avoidance); escape; extinction; drive; shock; motivation; strength; coercion. Para identificação das categorias de registro foi utilizada a ferramenta "localizar" do programa Adobe Reader. Os documentos que não estavam neste formato foram escaneados $\mathrm{e}$ convertidos e, quando isso não foi possível, foram lidos na íntegra no formato original.

Todos os documentos que continham pelo menos duas categorias de registro continuaram inclusos; os demais foram excluídos. Os documentos que permaneceram inclusos foram lidos integralmente em ordem cronológica. Após a leitura integral, quando foi observado que o documento, apesar de conter as categorias, não era pertinente ao trabalho, ele foi excluído.

\section{RESULTADOS E DISCUSSÃO}

Skinner fez descrições sobre a adequabilidade e eficácia da punição, apresentando, frequentemente, seus subprodutos nos anos 40,50, 60, 70 e 80. Isto significa que, com exceção dos anos 30, o tópico da punição apareceu de forma ubíqua em seus escritos. Estas descrições foram divididas em negativas (quando Skinner utilizou autoclíticos qualificadores negativos, como: desvantajoso, ruim, ineficaz) e positivas (quando Skinner identificou o uso da punição como importante ou salutar). A Tabela 1 mostra as descrições feitas por Skinner, de acordo com a divisão proposta, e as obras em que ocorreram.

De acordo com a Tabela 1, foram encontradas mais descrições negativas com relação a adequabilidade e eficácia da punição em Skinner, do que positivas. Essas descrições têm inícios nos anos 40 (Skinner, 1948) e se mantém até o final da obra do autor (Skinner, 1990). Foram encontradas três descrições identificadas como positivas que merecem maiores esclarecimentos.

A primeira delas foi encontrada em Skinner (1957/1992) na análise de comportamento verbal complexo:

Se punição é administrada habilmente suficiente para produzir "repressão bem sucedida", o resultado pode ser satisfatório, e em geral há um ganho considerável se a punição gerar um processo de edição por meio do qual comportamento verbal é emitido com "deliberação". . . . A performance do falante humano também é melhorada por punição branda. Se todas as respostas verbais de alguém fossem invariavelmente reforçadas, ele estaria constantemente ocupado com comportamento verbal. Uma mera redução na frequência relativa de reforçamento iria reduzir essa atividade, mas provavelmente não a um nível razoável. O processo de extinção, como empregado na discriminação, coloca o comportamento verbal sob controle apropriado de estímulos, mas as condições sob as quais comportamento verbal é reforçado são tão extensivas e tão confusas que alguma coisa a mais provavelmente é necessária. Os processos de edição gerados por punição aumentam muito a adequação do comportamento verbal a todas as características de uma ocasião, incluindo audiência (Skinner, 1957/1992, p. 379-380). 
Tabela 1

Descrições sobre adequabilidade e eficácia da punição na obra de B. F. Skinner

Descrições sobre adequabilidade e eficácia da punição
(1) Compativas
"melhores" ou "mais eficazes"
(2) Não funciona
(3) Uso defeituoso
(4) Contingência defeituosa
(5) Efetividade questionável
(6) Funcionamento desvantajoso em longo prazo, para o indivíduo punido e para agência
(7) Desvantagens da restrição física
(8) Produção de disposições emocionais desvantajosas para controlador e controlado
(9) Produção de disposições emocionais desorganizadoras
(10) Necessidade de controle remediativo posterior
(11) Custo na redução e eficiência geral e felicidade do grupo
(12) Efeito liquido prejudicial
(13) Não efetividade em longo prazo, em comparação com reforçamento positivo
(14)Consequências e subprodutos indesejáveis
(15) Consequências imprevisiveis
(16) Subprodutos infelizes
(17) Sérias desvantagens

Positivas

(1) Satisfatória (caso haja produção de "repressão bem-sucedida" e se for branda) em gerar processo de auto-edição do comportamento verbal (deliberação), aumentar a performance do falante, aumentando a adequabilidade do comportamento verbal a características de ocasião, incluindo audiência

(2) Salutar se utilizada de forma branda e por pequenas unidades de comportamento

(3) Importante na eliminação de comportamentos destrutivos
Obras

Skinner (1948; 1968a)

Skinner (1948)

Skinner (1953/2005)

Skinner (1968a)

Skinner $(1953 / 2005)$

Skinner $(1953 / 2005)$

Skinner $(1953 / 2005)$

Skinner $(1953 / 2005)$

Skinner $(1953 / 2005)$

Skinner $(1953 / 2005)$

Skinner (1953/2005)

Skinner (1968a)

Skinner (1968a)

Skinner (1988a; 1990)

Skinner (1971/2002)

Skinner (1976)

Skinner (1977/1978);

Skinner (1983) *

Skinner (1957/1992)

Skinner (1968a)

Skinner (1988a)

Nota: *Nessa obra Skinner se referiu a uma palestra que fez no "Mount Holyoke Institute" no verão de 1950, intitulada "Reward and Punishment in Occupation Policies".

Neste trecho, a punição branda é considerada como variável importante na produção de comportamento verbal apropriado, principalmente comportamento verbal lógico e científico, desde que ocorra repressão "bemsucedida", isto é, que respostas de fuga do estímulo aversivo condicional ocorram rapidamente, não havendo lugar para ocorrência de respostas emocionais. A punição é comparada com outros procedimentos que não teriam a mesma eficácia, portanto considerada como importante nessas situações.

A segunda descrição ocorreu em Skinner (1968a), onde ele considerou que a punição poderia ser eficaz se fosse branda e contingente à pequenas unidades de comportamento. Ele deu o exemplo da criança que está aprendendo a amarrar os sapatos: não se deveria punir a falha completa em amarrar os sapatos, mas se reprimendas brandas fossem apresentadas contingentes à pequenas partes de toda a cadeia de amarrar os sapatos, a topografia correta poderia ser modelada porque respostas incompatíveis são selecionadas dentro de um leque de possibilidades restritas. O mesmo poderia ser feito com comportamento verbal, onde pequenas punições brandas seriam contingentes à pequenos erros em um texto. Skinner afirmou que como a punição usada foi branda os subprodutos seriam minimizados, e, portanto, poderia haver resultados importantes.
E a última descrição positiva, ocorreu em Skinner (1988a):

Frequentemente se tem dito que eu sou contrário a todas as formas de punição, e eu gostaria de fazer a seguinte correção.

Punição é geralmente usada para a vantagem do punidor mas existem exceções, e elas podem algumas vezes ser justificadas. Algumas crianças autistas, por exemplo, irão se machucar seriamente ou se engajar em outros tipos de comportamento excessivo a menos que estejam sob efeito de drogas ou sejam contidas, e outro tratamento é virtualmente impossível. Se um estímulo aversivo breve e inofensivo administrado de maneira contingente ao comportamento autodestrutivo ou outro comportamento excessivo, suprime o comportamento e deixa a criança livre para desenvolver de outras formas, eu acredito que seja justificado (p. 1).

Nesse trecho Skinner (1988a) apresentou um possível uso da punição que seria positivo ou pelo menos aceitável. Entretanto, continuou o texto dizendo que permanecer satisfeito com uso da punição é que seria o real erro e que a alternativa seria o reforçamento positivo. 
O autor afirma que apenas foi dado início à utilização do reforçamento positivo no lugar da punição e nós ainda não descobrimos práticas não punitivas adequadas.

Subprodutos ou efeitos colaterais negativos fazem partes das descrições negativas sobre adequabilidade e eficácia da punição. A Tabela 2 mostra os subprodutos da punição e as obras de Skinner em que foram encontrados. Foi feita uma divisão entre: subprodutos genéricos (e.g., quando Skinner apresentou subprodutos da punição que não foram relacionados a nenhum agente punidor ou agência de controle específica) e subprodutos específicos (e.g., quando Skinner apresentou subprodutos produzidos pelo uso da punição em cada situação ou agência de controle especifica).

Observa-se que Skinner começou a apresentar subprodutos da punição desde a década de 1940 (Skinner, 1948) até os anos 90 (Skinner, 1990). O autor apresentou, na maioria das vezes, uma caracterização topográfica dos subprodutos da punição. Por exemplo, os subprodutos relacionados à educação, para o aluno, poderiam ser funcionalmente classificados como respostas de fuga, até mesmo medo e ansiedade, se levarmos em consideração que essas palavras descrevem padrões comportamentais que envolvem respondentes e operantes. Mas o autor optou por dar exemplos específicos de comportamentos (topográficos) que podem aparecer como efeitos colaterais da punição.

Assim como identificado por Martins, Carvalho Neto e Mayer (2013), os subprodutos descritos foram, na maioria, negativos. Vale a pena salientar que o subproduto "contra controle" pode ser também compreendido como positivo em Skinner (1971/2002). O autor chamou a atenção de que mesmo o reforçamento positivo pode ser utilizado em benefício do controlador e não do controlado (mau uso do reforçamento positivo). Por não gerar condições para fuga ou revolta (contra controle), o indivíduo se sente livre e não luta contra esse tipo de controle. Nesse sentido, o uso da punição teria a vantagem de ter efeitos conspícuos e gerar revolta, permitindo que as pessoas se rebelem contra seus controladores.

Tabela 2

Subprodutos da punição (genéricos e específicos) encontrados na obra de B. F. Skinner

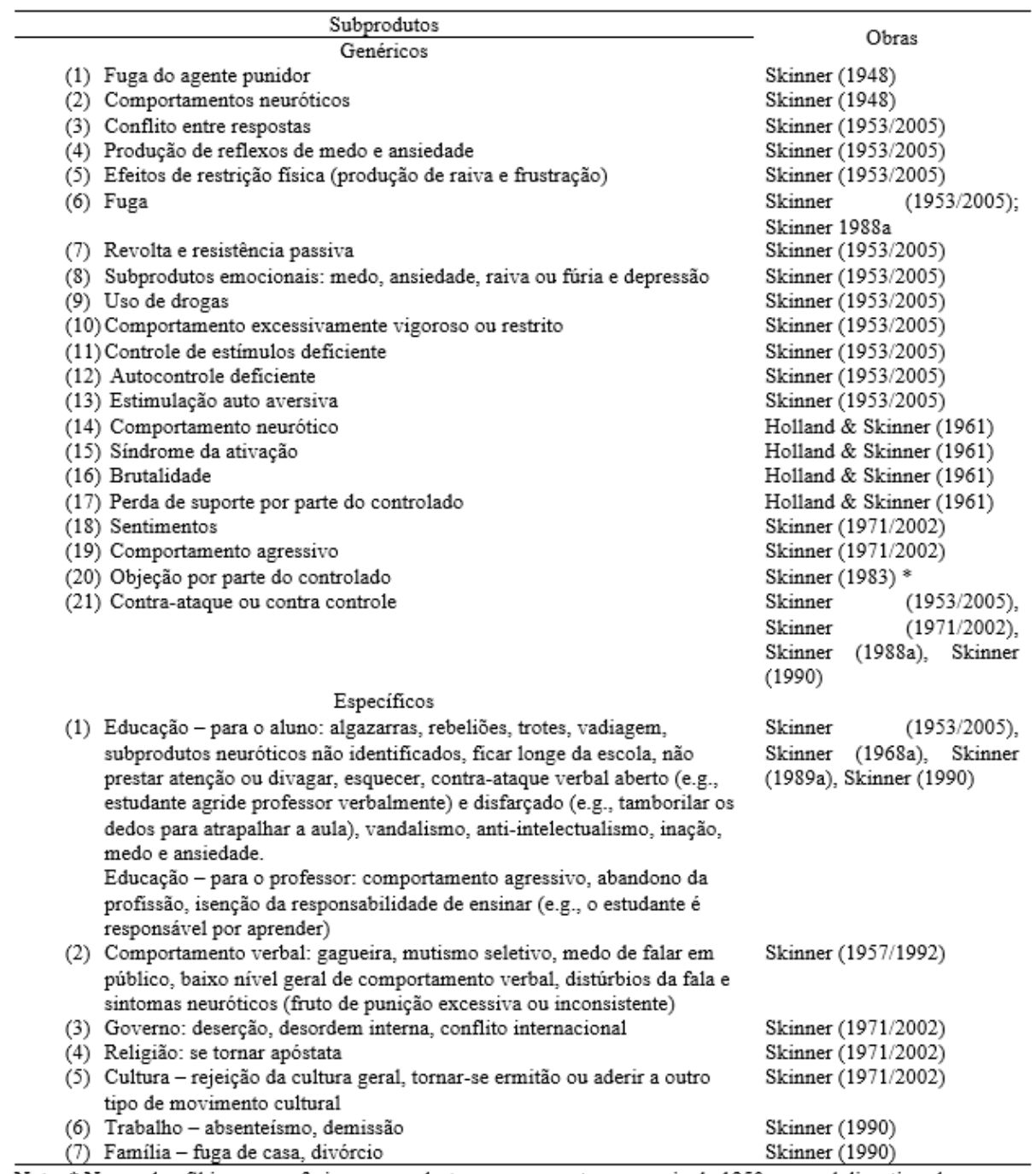

Nota: * Nessa obra Skinner se referiu a uma palestra que apresentou em maio de 1950 , na qual discutiu sobre controle do comportamento 
Por fim, identificou-se a "não" prescrição da punição para controle de comportamento. Em Walden II, Skinner (1948) retirou a punição como possibilidade de controle comportamental em sua comunidade: "Por um lado nós não punimos. Nós nunca administramos algo desagradável na esperança de reprimir e eliminar comportamento indesejável" (Skinner, 1948, p. 113). Ainda nessa obra, Skinner salientou que o planejamento cultural deveria cuidadosamente evitar a ameaça ou uso da força.

O fato de Skinner (1948) avaliar negativamente punição em Walden II, não significa que este tipo de controle ou que controle aversivo ${ }^{2}$, em geral, não esteja de forma alguma, presente na comunidade. Punição é utilizada na comunidade para lidar com rebanho de carneiros, com o uso da cerca eletrificada e depois da corda, e também na expansão territorial e econômica da comunidade, conforme identificado por Martins, Carvalho Neto e Mayer (2017). Além disso, o ensino de autocontrole pode ser considerado como uso de controle aversivo, pois há estruturação gradual de estímulos aversivos para construir tolerância

Ao falar sobre o treinamento ético, no qual a cultura, de maneira tradicional, se utiliza amplamente de punição, Skinner (1961/1999, 1966, 1968a, 1979b) tentou propor um tipo de planejamento cultural em que a punição não fosse utilizada. Em entrevista feita por Evans (Skinner, 1968b), Skinner admitiu que sua ênfase no reforçamento positivo refletia uma tendência histórica e cultural de transição do controle aversivo para práticas mais positivas. Em 1979, afirmou que "não gosta de punição, não gosta de ser punido e nem de ver os outros sendo punidos, e que a tarefa de uma ciência do comportamento deveria ser procurar substitutos para os métodos punitivos tradicionais" (Skinner, 1979c, p. 78).

Skinner (1983) contou sobre uma palestra proferida no Japão em 1979, que em 1990 se tornou um artigo (The Non Punitive Society). Skinner afirmou que se a punição sempre é dispensável ainda permanecia como uma questão. O autor discutiu a utilização de estímulos aversivos por Ivar Lovaas e Matthew Israel em centros para crianças autistas que demonstravam comportamentos auto ou heterolesivos severos. Skinner afirmou que Matthew Israel tinha uma lista organizada, em ordem de severidade, de estímulos aversivos, e que nenhuma forma mais severa era utilizada até que formas mais brandas fossem testadas. A lista foi liberada pelos jornais e as pessoas foram removidas daquele centro. Nessa passagem, Skinner parece ter uma posição mais cética com relação à avaliação da punição, compreendendo-a como uma questão a ser respondida.

No artigo mencionado acima, uma de suas últimas publicações, Skinner (1990) discutiu de forma concentrada a possibilidade de uma planejamento cultural não-punitivo. Segundo Skinner, o homem foi bemsucedido em lidar com eventos do mundo físico não social

\footnotetext{
${ }^{2}$ Skinner não usa o termo "controle aversivo" em Walden II, a distinção entre controle aversivo e punição apareceu posteriormente em sua obra (década de 1950)
}

que são "desagradáveis ou punitivos" (p. 1) como fome, doenças e trabalho exaustivo. Foram desenvolvidas tecnologias (e.g., agricultura, medicina, maquinário industrial) que tornaram possível que pelo menos alguma parcela da população, escapasse ou evitasse esses eventos. Todavia, a humanidade não foi tão bem-sucedida em lidar com eventos punitivos sociais, ou seja, com as formas de sofrimento que são impostas por alguns indivíduos aos outros.

Nesse momento, Skinner (1990) retomou a discussão sobre agências, discutindo como a punição é utilizada amplamente nos governos, escolas, indústria, algumas formas de psicoterapia e no cuidado com pessoas com algum transtorno de desenvolvimento ou personalidade. Além do uso institucionalizado, o autor também mencionou o uso cotidiano da punição nas relações interpessoais que pode ser verbal (e.g., críticas, reclamações, desaprovação) ou física (e.g., abuso físico de mulheres e crianças).

Skinner (1990) apresentou a "modificação do comportamento" que ele definiu como "aplicação da análise experimental do comportamento" (p. 4). A modificação do comportamento foi apresentada como um esforço para desenvolver alternativas à punição. Skinner se referiu basicamente ao uso de reforçamento positivo como estratégia e alertou que assim como a punição tem efeitos imediatos, mas produz perdas em longo prazo, o reforçamento positivo funcionaria de forma distinta, tendo poucos efeitos imediatos, mas ganhos em longo prazo. Essa característica explicaria, na visão de Skinner, porque a punição é amplamente utilizada ao invés de reforçamento positivo.

Skinner (1990) descreveu as aplicações da análise experimental do comportamento, baseada em contingências de reforçamento positivo, em diversas áreas como educação, psicoterapia e cuidado com pessoas com algum transtorno do desenvolvimento ou personalidade (e.g., produção de ambiente protéticos), prisões e centros de menores infratores. $\mathrm{O}$ autor afirmou que a única área em que o uso de reforçamento positivo ainda é limitado e visto com estranheza é o governo. Nesse momento, Skinner discutiu sobre combate ao crime e pena de morte, e assumiu um tom claramente prescritivo ao afirmar que "intensificação da punição não é uma solução" (p. 9). O autor deu o exemplo da Inglaterra onde, no século XVIII, duzentos crimes eram punidos com morte, um deles era o roubo de lenços de seda. $\mathrm{O}$ infrator era enforcado em praça pública e, portanto, se formava um espetáculo que reunia uma multidão, criando uma situação ideal para que os ladrões de lenços pudessem roubar, mesmo que seus "colegas" estivessem sendo enforcados naquele momento pela mesma infração.

Skinner (1990) finalizou assumindo, novamente, um tom prescritivo. Ele afirmou que pensar numa sociedade não punitiva soa utópico no sentido de impossível, quando se olha para o mundo em que vivemos (e.g., guerras, violência e terrorismo). Skinner acreditava que não se atingirá um mundo mais pacífico ou melhor aplicando análise experimental do comportamento na diplomacia internacional, ele recorreu a aplicações em 
menor escala: nas escolas, indústrias e relações interpessoais. O raciocínio do autor é que se as pessoas aprenderem a utilizar medidas não punitivas em suas vidas diárias, talvez, essas mesmas pessoas, ao lidarem com assuntos internacionais utilizem dessas medidas. Nas palavras do autor "É o infeliz e o amedrontado que recorre a guerra" (Skinner, 1990, p. 11).

De acordo com Skinner (1990) a busca por uma sociedade não punitiva é nada mais do que a busca pela felicidade. Ele defendeu que felicidade é um sentimento produzido não quando se age para evitar ou escapar da punição, mas quando se produz reforçadores positivos. A relação entre comportamento e consequência para ele é que é importante, não basta apenas viver rodeado de reforçadores positivos, eles precisam ser produzidos pelo indivíduo. Skinner afirma que um mundo feliz não irá ser atingido via estratégias punitivas e que a humanidade precisa resolver os seus problemas (e.g., superpopulação, esgotamento de recursos e poluição) sem recorrer a medidas aversivas, substituindo competição por cooperação. Caso contrário, segundo Skinner, o homem enfrentará sua própria extinção.

Nota-se, ao final do texto, um tom quase que profético ao anunciar o homem como causador de sua própria extinção. Mostra um Skinner como pensador da cultura e não mais do indivíduo, apesar de suas soluções serem sempre focadas no controle face a face, deixando clara a "não" prescrição da punição como forma de controle comportamental individual ou no planejamento cultural.

\section{CONSIDERAÇÕES FINAIS}

Pode-se afirmar que poucos temas relacionados ao comportamento humano tratados por Skinner não envolveram análises sobre punição ou do controle aversivo. O próprio autor reconheceu o uso ubíquo da punição e tentou apresentar razões para tal, como: (1) reforçamento positivo não é bem compreendido, seus efeitos não são tão conspícuos e punição tem efeitos mais rápidos; e (2) agir aversivamente teria um tipo de prioridade genética, pois repertórios agressivos, assim como a capacidade de adquiri-los teria valor de sobrevivência proeminente (Skinner, 1977/1978).

Apesar da punição estar frequentemente envolvida nas descrições skinnerianas, o autor apresentou mais aspectos pejorativos com relação ao seu uso, incluindo subprodutos, do que positivos. Skinner não prescreveu punição como uma alternativa para controle comportamental, em grande parte dos casos. Entretanto, alguns trechos mostraram que Skinner alternava entre um posicionamento mais rígido com relação ao não uso da punição e um posicionamento mais flexível, como foi demonstrado em sua opinião para tratamento de pessoas autistas (Skinner, 1988a). Esses dados vão de encontro aos dados de Martins, Carvalho Neto e Mayer (2013, 2017).

A maior parte das afirmações skinnerianas sobre a eficácia da punição e seus subprodutos foram frutos de interpretação. Há uma escassez de estudos sobre controle aversivo em geral (Baron, 1991; Catania, 2008) e os dados produzidos até aqui com não-humanos utilizaram em grande parte apenas o choque elétrico. Poucos desses estudos foram feitos pensando em alguma aplicação (Critchfield, 2014).

Somado a isso, poucos estudos têm se dedicado a estudar os subprodutos da punição. As revisões de literatura que abarcaram o tema (e.g., Lerman \& Vorndran, 2002; Newson, Favell, \& Rincover, 1983) apontam que poucos estudos têm examinado os subprodutos da punição em contextos clínicos e que os dados apresentados pelos estudos que o fazem, em geral, são frutos de observações anedóticas. Dessa forma, ao falar sobre os subprodutos descritos por Skinner, tem que se ter a cautela de considerar que, embora logicamente corretos, pouco se tem feito para estudá-los adequadamente em contextos controlados.

Critchfield (2014) identifica esse tipo de consideração generalizada dos efeitos deletérios da punição como uma das "verdades essenciais" da Análise do Comportamento, e que não tem passado pelo filtro cético adequado da comunidade. $\mathrm{O}$ autor faz ressalvas quanto a validade externa dos dados experimentais produzidos em laboratório, afirmando que algumas noções amplamente aceitas sobre punição podem ser questionadas fora do laboratório.

A posição de Critchfield (2014) pode gerar desconforto entre os analistas do comportamento, por propor a contestação do que parecem ser dogmas relacionados à punição que têm sido transmitidos de geração em geração. $\mathrm{O}$ mesmo posicionamento pode ser visto em Hunziker (2017). Critchfield reconhece essa possibilidade e traz uma saída ao afirmar que a comunidade deve assumir uma postura daqueles que "aceitam os dogmas e sabem disso" (p. 43). Em outras palavras, ele propõe que os estudantes sejam ensinados acerca dos efeitos deletérios da punição, com base nos dados produzidos e interpretações propostas, e que haja limitação do uso da punição na vida pessoal e no trabalho clínico, como tem sido frequentemente argumentado pela análise do comportamento.

Isso parece estar ocorrendo de forma bemsucedida dentro da disciplina. Reed e Lovett (2008) em uma pesquisa nacional sobre ética e eficácia da punição, realizada com membros da Associação para Análise do Comportamento (ABA), mostraram que, em geral, os participantes viam procedimentos de punição como menos eficazes em comparação com reforçamento positivo, que a punição tem mais efeitos colaterais do que reforçamento positivo e que deve ser empregada apenas contingente à comportamentos que produzem risco para o indivíduo ou para outras pessoas. Os participantes também não concordaram com a afirmação de que uso de punição é ético mesmo quando aprovado por um comitê ou que haja consentimento. Entretanto, para Critchfield (2014), é importante que a comunidade saiba que para o avanço da disciplina ela precisa estar aberta a novos dados e novas pesquisas.

Embora Skinner tenha sido frequentemente contrário ao uso da punição e de controle aversivo em geral, ele, ainda assim, foi identificado como um psicólogo a favor desse tipo de prática (Skinner, 1973; Skinner 1983) 
e responsabilizado pelo uso de técnicas aversivas com as quais nunca lidou (Skinner, 1983). Nas palavras de Skinner:

Eu gostaria de ver nenhuma punição. Eu nunca tive qualquer coisa a ver com terapia aversiva, embora quando eu estava na Inglaterra, há um ano atrás, eu os vi me culpando por Laranja Mecânica ${ }^{3}$, eu tenho sido tão severamente contra punição que alguns dos meus colegas tem tentado me psicanalisar para descobrir o porquê (Skinner, 1983, p. 282-283).

DeBell e Harless (1992) descreveram cinco mitos sobre Skinner nas teorias psicológicas, sendo um deles a crença de que Skinner via a punição como uma forma preferida de controle de comportamento. Cruz (2013) sustenta que análise do comportamento é um reflexo de alguns elementos idiossincráticos da vida acadêmica e institucional de B. F. Skinner. Sendo assim, faz sentido pensar que opiniões públicas sobre Skinner, provavelmente se estenderam para Análise do Comportamento como alguns estudos apontam (e.g., Morris \& Todd, 1992; Dinsmoor, 1992; Arntzen, Lokke, Lokke, \& Eilertsen, 2010; Lamal, 1995, Guimarães, 2003).

Alguns motivos podem ser levantados para tentar explicar essa má compreensão da posição de Skinner: (1) o uso de termo "controle" cujo significado na cultura popular está fortemente associado a condições desumanas; (2) o uso do termo "punição", um vernáculo popular cujo significado também está associado a condições desumanas. Apenas a título de ilustração, o próprio termo "controle" pode ter implicações aversivas para o leigo, tanto que autores como Hayes et al. (2011), sugerem o uso de "influência". Além disso, o termo "punição" também vem do vocabulário cotidiano e não técnico, então quando o analista do comportamento fala em punição, evoca intraverbais já estabelecidos em relação a esse estímulo no ouvinte.

Nota-se, portanto, que, dentro da Análise do Comportamento, as ideias de Skinner chegam a ser consideradas como utópicas ou por vezes dogmáticas com relação à não utilização da punição no controle do comportamento humano. Cenário oposto parece se estabelecer fora dessa comunidade, onde Skinner tem sido identificado como defensor do uso da punição. Os dados desse trabalho mostram que, de maneira geral, a posição de Skinner, mesmo que fruto de interpretação, se manteve estável ao longo de sua carreira, advogando contra o uso da punição e alertando com relação a seus subprodutos.

Se Skinner tem sido identificado como um psicólogo a favor da punição e se a Análise do Comportamento desenvolveu, enquanto prática, características do seu fundador, deriva-se que a área pode ser identificada como a favor de práticas punitivas. Se essa premissa for verdadeira, algumas perguntas surgem como: "o que essa representação de Skinner e da Análise do
Comportamento significam para nós enquanto comunidade?" A depender da resposta, teríamos que nos perguntar "se precisamos e, se sim, como podemos mudar essa "representação?".

Dentre as inúmeras soluções que possamos levantar, abandonar o estudo da punição não deveria ser uma delas. Muitos analistas do comportamento podem pensar que ao continuar a estudar punição nós poderíamos contribuir com essa "representação". Entretanto, para que alternativas a esse tipo de controle sejam desenvolvidas, nós devemos entender de forma clara como ele funciona. Esse entendimento pode ser satisfatório quando falamos de pesquisas básicas, com não humanos e com estímulos aversivos muito específicos (Critchfield, 2014). Todavia, a generalidade desses dados é colocada em questão quando nos deparamos com situações aplicadas, onde há uma variedade de condições e parâmetros de estímulo que são muito diferentes das condições de laboratório. Isso significa que o que aprendemos no laboratório não nos ajuda em nada? Claro que não, mas significa que nós deveríamos passar a pensar no laboratório de maneira translacional, isso é, tentar criar condições no laboratório que tenham maior complexidade e se aproximem das condições que vigoram no contexto aplicado.

\section{DECLARAÇÃO DE CONFLITO DE INTERESSES}

Os autores declaram que não há conflito de interesses relativos à publicação do artigo.

\section{CONTRIBUIÇÃO DE CADA AUTORA}

Os autores participaram suficientemente do trabalho para tornar pública sua responsabilidade pelo conteúdo. B. C. Santos contribuiu para concepção do trabalho, coleta de dados e redação final; M. B. Carvalho Neto contribuiu para a concepção do trabalho e supervisão da redação.

\section{DIREITOS AUTORAIS}

Este é um artigo aberto e pode ser reproduzido livremente, distribuído, transmitido ou modificado, por qualquer pessoa desde que usado sem fins comerciais. O trabalho é disponibilizado sob a licença Creative Commons 4.0 BY-NC.

\section{(cc) $\mathrm{BY}-\mathrm{NC}$}

\section{REFERÊNCIAS}

Andery, M. A., Micheletto, N., \& Sério, T. M. (2004). Publicações de B. F. Skinner: de 1930 a 2004. Revista Brasileira De Terapia Comportamental E Cognitiva, 6(1), 93-134. doi: 10.31505/rbtcc.v6i1.69

Arntzen, E., Lokke, J., Lokke, G., \& Eilertsen, D. (2010). On misconceptions about behavior analysis among university students and teachers. The Psychological Record, 60(2), 325-336. doi: 10.1007/BF03395710

\footnotetext{
${ }^{3}$ Filme lançado em 1971, dirigido por Stanley Kubric.
} 
Balsam, P. D., \& Bondy, A. S. (1983). The negative side effects of reward. Journal of Applied Behavior Analysis, 16(3), 283-296. doi: 10.1901/jaba.1983.16-283

Baron, A. (1991). Avoidance and punishment. In I. H. Iversen, \& K.A. Lattal (Eds.), Experimental analysis of behavior - Part I (pp. 173-217). Amsterdan: Elsevier.

Catania, C. A. (2008). The Journal of Experimental Analysis at zero, fifty, and one hundred. Journal of Experimental Analysis of Behavior, 89(1), 11-118. doi: 10.1901/jeab.2008.89-111

Critchfield, T. S. (2014). Skeptic's corner: Punishment Destructive force or valuable social "adhesive"? Behavior Analysis Practice, 7, 36-44. doi: 10.1007/s40617-014-0005-4

Crosbie, J. (1998). Negative reinforcement and punishment. In K. A. Lattal \& M. Perone (Eds.), Handbook of research methods in human operant behavior (pp. 163189). New York: Plenum Press.

Cruz, R. N. (2013). B. F. Skinner e a vida científica: Uma história de organização social da análise do comportamento. (Tese de doutorado). Universidade Federal de Minas Gerais, Belo Horizonte - MG, Brasil.

DeBell, C. S., \& Harless, D. K. (1992). B. F. Skinner: Myth and misperception. Teaching Psychology, 19(2), 68-73. doi: 10.1207/s15328023top1902_1

Dinsmoor, J. (1992). Setting the record straight: the social views of B. F Skinner. American Psychologist, 47(11), 1454-1463. doi: 10.1037/0003-066X.47.11.1454

Dittrich, A. (2004). Behaviorismo radical, ética e política: Aspectos teóricos do compromisso social (vol. I) (Tese de Doutorado). Universidade Federal de São Carlos, São Carlos - SP, Brasil.

Dittrich, A., \& Abib, J. A. D. (2004). O sistema ético Skinneriano e consequências para a prática dos analistas do comportamento. Psicologia: Reflexão e Crítica, 17(3), 427-433. doi: 10.1590/S010279722004000300014

Guimarães, R. P. (2003). Deixando o preconceito de lado e entendendo o Behaviorismo Radical. Psicologia: Ciência e Profissão, 23(3), 60-67. doi: 10.1590/S141498932003000300009

Hayes, S. C., Blackledge, J. T., \& Barnes-Holmes, D. (2001). Language and cognition: construction an alternative approach within the behavioral tradition. In D. Barnes Holmes e B. Roche (Eds.), Relation frame theory: A post-skinnerian account of human language and cognition (pp. 3-20). New York: Kluwer Academic/Plenum Publishers.

Hineline, P. N. (1984). Aversive control: A separate domain?. Journal of the Experimental Analysis of Behavior, 42(3), 495-509. doi: 10.1901/jeab.1984.42495
Holland, J. G., \& Skinner, B. F. (1961). The analysis of behavior: A program for self-instruction. New York: McGraw-Hill Book Company.

Hunziker, M. H. L. (2017). Dogmas sobre o controle aversivo. Acta Comportamentalia, 25(1), 85-100.

Lamal, P. A. (1995). College students' misconceptions about behavior analysis. Teaching Psychology, 22(3), 177-180. doi: 10.1207\%2Fs15328023top2203_3

Lerman, D. C., \& Vorndran, C. M. (2002). On the status of knowledge for using punishment: Implications for treating behavior disorders. Journal of Applied Behavior Analysis, 35(4), 431-434. doi: 10.1901/jaba.2002.35-431

Martins, T. E. M., Carvalho Neto, M. B., \& Mayer, P. C. M. (2013). B. F. Skinner e o uso do controle aversivo: Um estudo conceitual. Revista Brasileira de Terapia Comportamental e Cognitiva, 15(2), 5-17.

Martins, T. E. M., Carvalho Neto, M. B., \& Mayer, P. C. M. (2017). Walden Two: Uma sociedade utópica não aversiva? Revista Brasileira de Terapia Cognitiva $e$ Comportamental e Cognitiva, 19(1), 76-91. doi: 10.31505/rbtcc.v19i1.953

Morris, E. K.; \& Todd, J. T. (1992). Case histories in the great power of misrepresentation. American Psychologist, 47(11), 1441-1453. doi: 10.1037/0003066X.47.11.1441

Newson, C., Favell, J. E., \& Rincover, A. (1983). The side effects of punishment. In S. Axelrod \& J. Apsche (Eds.), The effects of punishment on human behavior (pp. 285-316). New York: Academic Press.

Reed, F. D. D., \& Lovett, B. J. (2008). Views on the efficacy and ethics of punishment: results from a national survey. International Journal of Behavioral Consultation and Therapy, 4(1), 61-67.

Santos, B. C. (2017). O conceito de punição na obra de B. F. Skinner: uma análise histórico-conceitual (19301990) (Tese de doutorado). Universidade Federal do Pará, Belém - PA, Brasil.

Skiba, R. J., \& Deno, S. (1991). Terminology and behavior reduction: The case against punishment. Exceptional Children, 57, 298-316.

Skinner, B. F. (1938). The behavior of organisms: an experimental analysis. Oxford, England: AppletonCentury.

Skinner, B. F. (1948). Walden II. New York: Macmillan.

Skinner, B. F. (1966). Contingencies of reinforcement in the design of a culture. Behavioral Science, 11, 159-166. doi: 10.1002/bs.3830110302

Skinner, B. F. (1968a). The technology of teaching. New York: Appleton-Century-Crofts.

Skinner, B. F. (1968b). Interview: Aversive versus positive control of behavior. R. I. Evans (Interviewer). In $B . F$. 
Skinner: The Man and his ideas (pp. 27-55). New York: E. P. Duton \& CO., INC.

Skinner, B. F. (1973). On corporal punishment [Letter to Editor]. Educational Leadership, 31, 61.

Skinner, B. F. (1976). About behaviorism. New York: Vintage Books. (Trabalho original publicado em 1974).

Skinner, B. F. (1976b). Particulars of my life:Part one of an autobiography. New York, NY: Alfred A. Knopf.

Skinner, B. F. (1978). Human behavior and democracy. In B. F. Skinner, Reflections on behaviorism and society (pp. 3-15). Englewood Cliffs: Prentice-Hall (Trabalho original publicado em 1977 sob o título: Between freedom and despotism).

Skinner, B. F. (1979a). The shaping of a behaviorist: Part two of an autobiography. New York, NY: Alfred A. Knopf.

Skinner, B. F. (1979b). Getting more milage out of incetives. Daniel Yergin (Interviewer). Psychology Today, 12, 18-28.

Skinner, B. F. (1979c). Interview. Michael Hollingshead (Interviewer). Omni, September, 77-80.

Skinner, B. F. (1980). Contingências do reforço: Uma análise teórica. Tradução realizada por R. Moreno. Coleção os pensadores. São Paulo: Abril Cultural. (trabalho original publicado em 1969).

Skinner, B. F. (1983). A matter of consequences: Part three of an autobiography. New York: Alfred A. Knopf.

Skinner, B. F. (1988a). A statement on punishment. APA Monitor, June, 22.

Skinner, B. F. (1989). Recent issues in the analysis of behavior. Columbus, $\mathrm{OH}$ : Merrill.

Skinner, B. F. (1990). The non-punitive society. Japanese Journal of Behavior Analysis, 5, 98-106. doi: 10.24456/jjba.5.2_87

Skinner, B. F. (1992). Verbal behavior. Cambridge, MA: B. F. Skinner Foundation (Trabalho original publicado em 1957).

Skinner, B. F. (1999). The design of cultures. In V. G. Laties \& A. C. Catania (Eds.), Cumulative record: Definitive Edition (pp.39-50). Acton, MA: Copley Publishing Group. (Trabalho original publicado em 1961).

Skinner, B. F. (2002). Beyond and freedom and dignity. Indianopolis/Cambrigde: Hackett Publishing Company, Inc. (Trabalho original publicado em 1971).

Skinner, B. F. (2005). Science and human behavior. Cambridge, MA: The B. F. Skinner Foundation (Trabalho original publicado em 1953).

Skinner, B. F., \& Vaughan, M. E. (1983). Enjoy old age: A program of self-management. New York: W. W. Norton.
Todorov, J. C. (2001). Quem tem medo de punição? Revista Brasileira de Terapia Comportamental e Cognitiva, 3(1), 37-40.

Submetido em: 26/03/2019

Aceito em: 14/06/2019 